\title{
The Effect of Gas Pressure on NO Conversion Energy Efficiency in Nonthermal Nitrogen Plasma
}

\author{
Morris D. Argyle \\ mdargyle@byu.edu \\ Gui-Bing Zhao \\ S.V.B. Janardhan Garikipati \\ Xudong $\mathrm{Hu}$ \\ Maciej Radosz
}

Follow this and additional works at: https://scholarsarchive.byu.edu/facpub

Part of the Chemical Engineering Commons

\section{Original Publication Citation}

G.B. Zhao, S.V.B. Janardhan Garikipati, X. Hu, M.S. Argyle, M. Radosz, "The Effect of Gas Pressure on NO Conversion Energy Efficiency in Non-Termal Plasma Reactors." Chemical Engineering Science, 6 1927-1937, 25. http://www.sciencedirect.com/science/journal/9259/6/7

\section{BYU ScholarsArchive Citation}

Argyle, Morris D.; Zhao, Gui-Bing; Garikipati, S.V.B. Janardhan; Hu, Xudong; and Radosz, Maciej, "The Effect of Gas Pressure on NO Conversion Energy Efficiency in Nonthermal Nitrogen Plasma" (2004). Faculty Publications. 406.

https://scholarsarchive.byu.edu/facpub/406

This Peer-Reviewed Article is brought to you for free and open access by BYU ScholarsArchive. It has been accepted for inclusion in Faculty Publications by an authorized administrator of BYU ScholarsArchive. For more information, please contact ellen_amatangelo@byu.edu. 


\title{
The Effect of Gas Pressure on NO Conversion Energy Efficiency in Nonthermal Nitrogen Plasma
}

\author{
Gui-Bing Zhao, S. V. B. Janardhan Garikipati, Xudong Hu, Morris D. Argyle, Maciej Radosz \\ Department of Chemical \& Petroleum Engineering, University of Wyoming, Laramie, WY \\ 82071-3295, USA
}

\begin{abstract}
This work explores the effect of gas pressure on the rate of electron collision reactions and energy consumption for $\mathrm{NO}$ conversion in $\mathrm{N}_{2}$ in a pulsed corona discharge reactor. A previous study showed that the rate constant of electron collision reactions, multiplied by the electron concentration, can be expressed as $\mathrm{k}[\mathrm{e}]=\beta \alpha^{-0.5} \mathrm{P}^{-0.5} \mathrm{~W}^{0.75} \exp (-\alpha \mathrm{P} / \mathrm{W})$. The model parameter $\alpha$ remains constant with increasing gas pressure, which verifies the previous assumption that the electron temperature is inversely proportional to gas pressure. However, the model parameter $\beta$ decreases with increasing gas pressure, which indicates that the rate constant of electron collision reactions decreases with increasing gas pressure. The new expression for the rate constant of electron collision reactions, $\mathrm{k}[\mathrm{e}]=\mathrm{B} \alpha^{-0.5} \mathrm{P}^{-1.4} \mathrm{~W}^{0.75} \exp (-\alpha \mathrm{P} / \mathrm{W})$, is more general because it explicitly accounts for the effect of gas pressure that was previously contained in the parameter $\beta$. The electron mean energy decreases with increasing gas pressure, which results in thermal dissipation of a larger fraction of the energy input to the reactor that heats the gas instead of producing plasma chemical reactions. Therefore, energy efficiency for NO conversion in $\mathrm{N}_{2}$ decreases with increasing gas pressure.
\end{abstract}

Submitted to Chem. Eng. Sci.

*Corresponding author. E-mail: radosz@uwyo.edu, tel: 307-766-2500, fax: 307-766-6777 


\section{Introduction}

Environmental regulations governing the emission of harmful gases into the atmosphere, such as $\mathrm{NO}_{\mathrm{x}}$, require efficient abatement methods. Among the emerging technologies for $\mathrm{NO}_{\mathrm{x}}$ conversion, nonthermal plasma is one of the most promising. A pulsed corona discharge reactor (PCDR) is one of the nonthermal plasma technologies, characterized by low gas temperature but high electron temperature, achieved by producing high energy electrons in the gas while leaving the bulk temperature of the gas unchanged. A PCDR utilizes a high-voltage, short-duration ( $<100 \mathrm{~ns}$ ) electrical discharge between non-uniform electrodes to produce streamers through the growth of electron avalanches formed by electron collision ionization events in the gas (Raether, 1964). A streamer is a region of highly ionized gas where a wide range of active radicals and chemical species are formed through electron collision reactions with the background gas. These active species, in turn, initiate bulk phase reactions that lead to $\mathrm{NO}_{\mathrm{x}}$ conversion to nitrogen and oxygen.

One of the major concerns for applications of nonthermal plasma is the energy consumption. Currently, reported energy costs for using nonthermal plasma processes to decompose $\mathrm{NO}_{\mathrm{x}}$ vary considerably [e.g., from 70 to $780 \mathrm{eV} /$ molecule (Yamamoto et al., 2000)]. All of these reported values of energy consumption represent low energy efficiencies because $\mathrm{N}$ atoms, which are one of the main active species responsible for $\mathrm{NO}_{\mathrm{x}}$ conversion (Zhao et al., 2004b), can be formed from $\mathrm{N}_{2}$ dissociation at much lower energies (i.e., the dissociation energy is $9.8 \mathrm{eV} /$ molecule). Although many investigators proposed that energy consumption of $\mathrm{NO}_{\mathrm{x}}$ conversion can be reduced by the optimization of the reactor configuration, [such as changing electrode diameter (Abdel-Salam et al., 2003), reactor length (Namihira et al., 2001), type of discharge (Penetrante et al., 1995), and series/parallel reactor configurations (Zhao et al., 2004a; Zhao et al., 2004c)], 
only a few investigators recognized that optimization of reactor pressure is also an important factor for reducing energy cost in conversion of NO using a PCDR. Starikovskaia et al. (2001) investigated the structure of the electrical breakdown in low-temperature pulsed discharges and found that there is an optimal pressure range for the development of the uniform nanosecond breakdown, in which maximum energy (around 60\%) goes into gas excitation to produce the reactive species. They also found that the energy distribution and ionization efficiency vary with the reactor pressure. Spiliopoulos et al. (1997) found that the electron collision reaction rates also vary with pressure due to the dependence of the mean electron energy or the electron energy distribution on the reactor pressure. Huang and Suib (1993) recognized that pressure is an important parameter for plasma reactors. Their experimental and theoretical studies both showed that the energy efficiency varies with pressure and that there is an optimal pressure for maximum energy efficiency. A more recent kinetic model for $\mathrm{NO}_{\mathrm{x}}$ decomposition in a PCDR (Hu et al., 2003; Zhao et al., 2004d) predicted that the rate of electron collision reactions should depend on the reactor pressure.

The goal of this work is to investigate such pressure effects not only on the rate of electron collision reactions, but also on energy efficiency of $\mathrm{NO}_{\mathrm{x}}$ conversion from 1.46 atm to 2.82 atm (absolute), which is the typical range of the diesel engine exhaust pressure (Anderson, 1957; Lilly, 1984).

\section{Experimental}

The pulsed corona discharge reactor used in this work consisted of a high-voltage power supply with control unit and the pulser/reactor assembly, as explained in detail elsewhere (Hu et al., 2002). The high voltage controller contained electronic and gas controls required to regulate 
the high voltage charging power supply as well as the pulsed power delivered to the reactor gas. The pulser/reactor assembly contained the pulsed power generator and the pulsed corona discharge reaction tubes. The reactor had ten parallel stainless steel tubes, each $914 \mathrm{~mm}$ in length and $23 \mathrm{~mm}$ in diameter, with a stainless steel wire, $0.58 \mathrm{~mm}$ in diameter, passing axially through the center of each tube. The wire was positively charged and the tube was grounded. The gas flowing through the reactor tube was converted to a plasma by high voltage discharge from the reactor anode. One tube was fitted with UV-grade quartz windows for diagnostics and plasma observation. The reactor pressure was varied using a control valve in the reactor outlet line. The number of parallel-reactor tubes used in a given experiment was varied by installing a wire in each active tube and sealing the unused tubes with Teflon corks with O-rings. The energy delivered to the reactor per pulse can be calculated either from time integral of the product of the measured pulse discharge voltage $(\mathrm{V})$ and current (I) or from $1 / 2 \mathrm{CV}_{c}{ }_{c}^{2}$, where $\mathrm{C}$ is the pulse forming capacitance $(800 \mathrm{pF})$ and $\mathrm{V}_{\mathrm{c}}$ is the charge voltage before discharge. The discrepancy between the calculated values for energy per pulse using above two methods is less than $3 \%$. Since the current can fluctuate and may be shifted in phase relative to voltage, the second method should be more accurate. Therefore, the energy input per pulse is calculated as $1 / 2 \mathrm{CV}_{c}$ in this work. The power consumed ( $\mathrm{W}$, in Watts) is calculated as the product of the energy per pulse and the pulse frequency. The system design permitted variation and measurement of applied voltage and its frequency, reactor current and reactor voltage.

The experimental test matrix is shown in Table 1 . The test gas mixture of NO in $\mathrm{N}_{2}$ was introduced into the PCDR at ambient temperature, around $300 \mathrm{~K}$, and at different reactor pressures ranging from $1.46 \mathrm{~atm}$ to $2.82 \mathrm{~atm}$ (absolute). Gas samples were collected from a common header at the discharge end of the PCDR in small stainless steel cylinders and analyzed 
for stable species using a Spectrum 2000 Perkin-Elmer Fourier transform infrared (FTIR) spectrometer with a narrow-band mercury cadmium telluride (MCT) detector.

Energy consumption analysis of the PCDR was one of the main tasks in this work. The voltage and current pulses were the source of energy for the gas. As found previously (Zhao et al., 2004b), $\mathrm{NO}_{2}$ and $\mathrm{N}_{2} \mathrm{O}$ are formed as byproducts when $\mathrm{NO}$ is converted in $\mathrm{N}_{2}$. Therefore, total $\mathrm{NO}_{\mathrm{x}}$ conversion was calculated, rather than $\mathrm{NO}$ conversion, because total $\mathrm{NO}_{\mathrm{x}}$ conversion reflects the degree of direct decomposition of $\mathrm{NO}$ into $\mathrm{N}_{2}$ and $\mathrm{O}_{2}$. Total $\mathrm{NO}_{\mathrm{x}}$ conversion was defined as the amount of $\mathrm{NO}$ converted to $\mathrm{N}_{2}$ as follows

$$
\begin{aligned}
\mathrm{NO} & \rightarrow \mathrm{NO}_{2}+\mathrm{N}_{2} \mathrm{O}+\mathrm{N}_{2}+\mathrm{O}_{2} \\
X_{\mathrm{N}_{2}} & =\frac{C_{i, \mathrm{NO}}-C_{o, \mathrm{NO}}-C_{o, \mathrm{NO}_{2}}-2 \times C_{o, \mathrm{~N}_{2} \mathrm{O}}}{C_{i, \mathrm{NO}}} \times 100 \%
\end{aligned}
$$

and the corresponding energy consumption, En, in eV per NO molecule converted to benign gases, $\mathrm{N}_{2}$ and $\mathrm{O}_{2}$, is expressed below in terms of total $\mathrm{NO}_{\mathrm{x}}$ conversion

$$
E n=\frac{W}{C_{i, \mathrm{NO}} \cdot X_{N_{2}} \cdot F} \times 1.0364 \times 10^{-5}
$$

where $C_{i}$ is the concentration at the reactor inlet $\left(\mathrm{mol} / \mathrm{m}^{3}\right), \mathrm{C}_{\mathrm{o}}$ is the concentration at the reactor outlet $\left(\mathrm{mol} / \mathrm{m}^{3}\right), \mathrm{X}_{\mathrm{N} 2}$ is the total conversion of $\mathrm{NO}$ to $\mathrm{N}_{2}, \mathrm{~W}$ is power input $(\mathrm{J} / \mathrm{s}), \mathrm{F}$ is flow rate $\left(\mathrm{m}^{3} / \mathrm{s}\right)$, and $1.0364 \times 10^{-5}$ is the conversion factor for $\mathrm{J} / \mathrm{mol}$ to $\mathrm{eV} / \mathrm{molecule}$. On the basis of prior work (Zhao et al., 2004b; Zhao et al., 2004d), a total of 20 reactions with two electron collision reactions, shown in Table 2, were selected to simulate the system of NO in $\mathrm{N}_{2}$.

The plasma reactor described above was modeled using a lumped kinetic model that describes the concentrations of all species as functions of the experimental variables, reported elsewhere (Zhao et al., 2004d). The important model parameters embodying the rate of electron collision reactions are $\alpha$ and $\beta$, as shown in Eq. (4), 


$$
k[e]=\beta \sqrt{\frac{1}{\alpha P}} W^{0.75} \exp \left(-\frac{\alpha P}{W}\right)
$$

where $\mathrm{k}$ is the rate constant of the electron collision reaction $\left(\mathrm{cm}^{3} \cdot \mathrm{mol}^{-1} \cdot \mathrm{s}^{-1}\right)$, [e] is the concentration of electrons $\left(\mathrm{mol} / \mathrm{cm}^{3}\right), \mathrm{W}$ is the power input $(\mathrm{J} / \mathrm{s})$, and P is the system pressure (atm). The parameters $\alpha$ and $\beta$ were determined from experimental data using a previously presented optimization method (Zhao et al., 2004d).

\section{Results and Discussion}

\section{Effect of reactor pressure on discharge}

The important initiating reactions in the corona discharge are caused by the collisions of energetic electrons, produced by the electrical discharge, with gas molecules in the reactor. Therefore, the rate of electron collision reactions directly determines the rate of $\mathrm{NO}_{\mathrm{x}}$ conversion. A fingerprint of the electron collision reactions in the PCDR is a discharge voltage versus time plot (waveform), which characterizes the properties of the streamers around the discharge wire. Figure 1 shows discharge voltage waveforms for five different reactor pressures using a two-tube reactor at $200 \mathrm{~Hz}$ pulse frequency. The discharge voltage waveforms can be divided into two sections. The first section is the initial peak, where the discharge voltage increases from zero to a maximum and then decreases back to zero. Approximately $99 \%$ of the total energy to the PCDR is delivered in this first section, which corresponds to energy dissipated for streamer propagation. The second section contains the subsequent fluctuations of discharge voltage, which correspond to energy dissipated after streamer propagation. As discussed by Mok et al. (1998), the second section of the energy input produces only slow electrons that do not contribute to the formation of active species because the energy delivered after streamer 
propagation is mainly used to sustain the low conductivity streamer channel and produce secondary streamers. Therefore, the important characteristics of the discharge streamer can be described by the first section of the discharge voltage. The main parameters that influence the properties of the streamers are the rise rate, pulse width and the peak value of the applied voltage (Hackam and Akiyama, 2000; van Veldhuizen et al., 1990; Creyghton et al., 1991a; Creyghton et al., 1991b), which are shown in Table 3 for different pressures. These results show that pulse peak value and rise rate are not affected by the reactor pressure. However, the pulse width, defined as the base width of the first peak at the point that it crosses the time axis, increases with increasing reactor pressure. Pulse width is an important parameter that affects energy efficiency of plasma chemical reactions. Generally, short pulses are more energy efficient than long pulses (Puchkarev and Gundersen, 1997; Hackam and Akiyama, 2000).

In the PCDR, all active species responsible for $\mathrm{NO}_{\mathrm{x}}$ conversion are produced through energetic electron collisions with background gases or the collisions between the molecules and ions, which are accurately described by the streamer propagation mechanism (Sigmond, 1984). A positive streamer (as in our reactor, in which the wire is the anode) is a potential ionizing wave, which propagates against the direction of electron drift. Electrons gain energy during drift from cathode to anode through acceleration in the imposed external electric field and spacecharge field close to streamer head. As electrons drift, they loose their energy through collisions with neutral gas molecules. Therefore, on average, electrons can be accelerated only over the mean free path of the neutral gas molecules, which decreases with increasing pressure. Thus, electron velocity before collision with neutral gas molecules decreases with increasing gas pressure, which means that the average electron drift velocity decreases with increasing gas pressure. This is consistent with Creyghton's (1994) conclusion that the electron drift velocity 
decays with increasing gas pressure to the -0.8 power. Therefore, the streamer propagation velocity decreases and the width of the discharge voltage pulse increases with increasing gas pressure, which explains the data in Table 3.

\section{Effect of reactor pressure on model parameters}

The previous discussion explains that gas pressure affects the electrical discharge properties in a PCDR. Therefore, gas pressure affects the rate of electron collision reactions. $\underline{\text { A previous }}$ study (Zhao et al., 2004d) showed that the rate constant of electron collision reactions, multiplied by the electron concentration, can be expressed as in Eq.(4). The parameters $\alpha$ and $\beta$ were determined for the five different pressures tested in the two-tube reactor using a previously presented optimization method (Zhao et al., 2004d). Figure 2 shows the experimental data and the correlated data for $\mathrm{NO}, \mathrm{NO}_{2}$ and $\mathrm{N}_{2} \mathrm{O}$ concentrations at the reactor outlet. The good agreement between the experimental data and the correlated data indicates that the twoparameter model accurately characterizes the kinetics of electron collision reactions R1 and R2.

Figure 3 shows the effect of reactor pressure on the model parameter $\alpha$ for electron collision reactions R1 and R2; $\alpha$ is nearly constant with reactor pressure. One of the assumptions for the kinetic model developed in our previous work (Zhao et al., 2004d; Hu et al., 2003) was that the electron temperature is inversely proportional to the reactor pressure, as in Eq. (5)

$$
k_{\mathrm{B}} T_{e}=\frac{E^{0} W}{\alpha P}
$$

where $k_{B}$ is the Boltzmann constant, $T_{e}$ is the electron temperature, $E^{0}$ is the activation energy for an electron collision reaction to occur, $\mathrm{W}$ is the input power, $\alpha$ is a constant of proportionality and $\mathrm{P}$ is the absolute reactor pressure. According to Eq. (5), when pressure increases, the 
electron temperature decreases. Hence, $\alpha$ should remain constant with varying reactor pressures as shown in Figure 3, which validates the underlying assumption.

Figure 4 shows the effect of pressure on the model parameter $\beta$ for electron collision reactions R1 and R2. Parameter $\beta$ is inversely proportional to $0.9^{\text {th }}$ power of reactor pressure, based on a least squares regression analysis. Thus, $\beta$ can be expressed as

$$
\beta=B \cdot P^{-0.9}
$$

where B is a constant of proportionality, and substituted in Eq. (4) as follows:

$$
\mathrm{k}[\mathrm{e}]=\mathrm{B} \alpha^{-0.5} \mathrm{P}^{-1.4} \mathrm{~W}^{0.75} \exp (-\alpha \mathrm{P} / \mathrm{W})
$$

Figure 5 shows values of the rate constant of electron collision reactions as a function of power input, calculated from Eq. (7) with the values of $\alpha$ and $\beta$ given in Table 4 for five different reactor pressures, in which $\alpha$ and $\beta$ are shown in Figure 3 and 4, respectively, and B is obtained from Eq. (6). The rate constant for both electron collision reactions R1 and R2 increases with increasing power input. However, the rate constant for both electron collision reactions decreases with increasing gas pressure at the same power input. Similar results were obtained by Lowke and Morrow (1995). As discussed above, the electron drift velocity decreases with increasing gas pressure, which means that the mean electron energy decreases with increasing gas pressure. Having analyzed the dissipation of input electrical power as a function of the average kinetic energy of the electrons, Penetrante et al. (1997) found that the fraction of input power consumed in electron collision processes leading to dissociation of $\mathrm{N}_{2}$ decreases with decreasing electron mean energy. Thus, the rate constant of electron collision reactions decreases with increasing gas pressure.

\section{Model prediction}


Previous investigations (Zhao et al., 2004a; Zhao et al., 2004d) showed that the lumped model accurately predicts the effects of varying gas residence time, initial NO concentration and power input. However, the pressure dependence of model parameter $\beta$ required different sets of $\beta$ parameters to accurately predict the experimental results at different reactor pressures. The experiments on $\mathrm{NO}$ conversion in $\mathrm{N}_{2}$ in one and ten-tube reactors at different pressures, shown in Table 1, were conducted to test the validity of Eq. (6) in describing the pressure dependence of $\beta$. Table 4 shows parameters $\alpha, \beta$ and $\mathrm{B}$ for the one and ten-tube reactors at different pressures. As discussed above, $\alpha$ does not vary with pressure (Figure 3). While $\beta$ does vary with pressure (Figure 4), B is indeed constant, which confirms the validity of Eq. (6). Figures 6 and 7 show the experimental and predicted $\mathrm{NO}_{\mathrm{x}}$ outlet concentrations as a function of power input in the one-tube reactor at 2.14 atm and 2.82 atm, respectively. Figure 8 shows similar data for the tentube reactor at $2.14 \mathrm{~atm}$. The good agreement between the model, which was based on experimental data obtained at 1.46 atm (Zhao et al., 2004a), and the experimental results obtained at different pressures in this work, verifies that the modified expression, Eq. (7), for the rate constant of electron collision reactions is more general because it includes the effect of gas pressure that was previously contained in the parameter $\beta$. The data in Table 4 show that parameter B is a constant for a given reactor geometry, but B varies with reactor geometry, as does $\beta$, which was described in detail elsewhere (Zhao et al., 2004a).

The model results in Figures 2 and 6-8 show that there are always maxima in $\mathrm{NO}_{2}$ and $\mathrm{N}_{2} \mathrm{O}$ concentrations as a function of input power under a variety of different experimental conditions, including varying reactor pressure, gas flowrate, initial NO concentration and number of parallel reactor tubes used. The low $\mathrm{N}_{2} \underline{O}$ concentrations $(<15 \mathrm{ppm})$ are difficult to measure experimentally and result in larger deviations between the model predictions and experimental 
data than those observed for $\mathrm{NO}$ and $\mathrm{NO}_{2}$ (as shown in Figures 2 and 6-8). The lumped model calculations show that $\mathrm{N}_{2} \mathrm{O}$ concentration reaches a stable value, and $\mathrm{N}_{2} \mathrm{O}$ cannot be further converted at higher power inputs [see Figures 2(a), 2(b), 7(c) and 8(c)]. The explanation for these maxima is described elsewhere (Zhao et al., 2004a).

The maxima in $\mathrm{NO}_{2}$ and $\mathrm{N}_{2} \mathrm{O}$ concentration increase with increasing reactor pressure, as shown in Figure 2. The rate of the tri-molecular reaction that forms $\mathrm{NO}_{2}$, $\mathrm{R} 4$ (Zhao et al., 2004d), increases as the concentrations of $\mathrm{NO}$ and $\mathrm{N}_{2}$ increase with increasing reactor pressure, which produces the larger maxima in $\mathrm{NO}_{2}$ concentration at higher reactor pressures. The increase in $\mathrm{NO}_{2}$ concentration increases the $\mathrm{N}_{2} \mathrm{O}$ formation rate by increasing the reaction rate of R5. The quenching rate of $\mathrm{N}_{2}(\mathrm{~A})$, which is the lowest-energy electronic excited state of $\mathrm{N}_{2}$, by NO (R10) also increases with increasing reactor pressure, which further contributes to the larger maxima in $\mathrm{N}_{2} \mathrm{O}$ concentration at higher pressures.

\section{Effect of reactor pressure on energy consumption of NO conversion}

Energy consumption analysis is one of the major concerns of this work. Previous investigations (Zhao et al., 2004a; Zhao et al., 2004d) proved that the lumped model accurately describes the effect of varying initial concentrations of NO and gas residence times. The analysis above shows that the model also accurately describes the effect of reactor pressure using Eq. (7). Therefore, this model was used to investigate the energy consumption for NO conversion at different gas pressures using different power inputs and gas residence times. For convenience of comparison, reaction systems with the same initial concentration (600 ppm NO in $\mathrm{N}_{2}$ ) in a two-tube reactor were evaluated in the following study. 
Figure 9(a) shows NO conversion and Figure 9(b) shows energy consumption as functions of power input, while Figure 9(c) shows energy consumption as a function of NO conversion in the two-tube reactor for different gas pressures at a gas residence time of 6 seconds. The model parameters $\alpha$ and B for electron collision reactions R1 and R2 shown in Table 4 were used to calculate the results shown in Figure 9. NO conversion and the associated energy consumption were calculated from Eq. (2) and (3).

Figure 9(a) shows that the NO conversion gradually increases with power input until a particular power is reached (e.g., $\sim 40 \mathrm{~W}$ for $1.46 \mathrm{~atm}$ ), after which the conversion reaches a stable value of $\sim 98-99 \%$ because of the difficulty in converting $\mathrm{N}_{2} \mathrm{O}$, as explained by Zhao et al. (2004a). However, the NO conversion at a given power input decreases with increasing reactor pressure for two reasons. First, the rate of electron collision reactions (e.g., e $+\mathrm{A} \rightarrow \mathrm{B}+\mathrm{e}$ ) can be expressed as

$$
r_{A}=k[e] C_{A}
$$

where $r_{A}$ is the rate of electron collision reaction and $C_{A}$ is the concentration of gas $A$, which can be expressed as follows

$$
C_{A}=\frac{P_{A}}{R T}
$$

where $\mathrm{P}_{\mathrm{A}}$ is the partial pressure of component $\mathrm{A}, \mathrm{R}$ is the gas constant and $\mathrm{T}$ is the gas temperature. Substituting Eq. (7) and Eq. (9) into Eq. (8), we obtain

$$
r_{A}=\frac{B}{R T} \cdot \sqrt{\alpha} \cdot P^{-0.4} \cdot W^{0.75} \cdot \exp \left(-\frac{\alpha P}{W}\right)
$$

Eq. (10) shows that the rate of electron collision reactions decreases with increasing reactor pressure. Second, the specific energy input to the reactor, in joules per mole, decreases with 
increasing gas pressure at a given power input and gas residence time. Therefore, the conversion of NO decreases with increasing gas pressure.

Figure 9(b) shows that, with increasing power input, energy consumption for NO conversion decreases rapidly at low power inputs, before reaching a flat minimum at intermediate power inputs, and finally increasing linearly at high power inputs. The initial decrease of energy consumption with increasing power input (below about $20 \mathrm{~W}$ ) is consistent with the exponential term in Eq. (10), which increases exponentially from zero as power input increases from zero. As a result, the rate of electron collision reactions exponentially increases with increasing power input. The discharge energy is therefore more efficiently consumed by electron collision reactions that initiate NO decomposition reactions, resulting in the sharp initial decline in energy consumption. The final linear increase of energy consumption with increasing power input is associated with the production of $\mathrm{N}_{2} \mathrm{O}$, which cannot be converted into $\mathrm{N}_{2}$ and $\mathrm{O}_{2}$, as explained previously (Zhao et al., 2004a). The results show that there is an optimal power input corresponding to minimal energy, which indicates that the operating conditions of the PCDR can be optimized in order to decrease energy consumption. A similar conclusion can be drawn from the experimental data provided by Mizuno et al. (1995).

Figure 9(c) shows that energy consumption decreases with increasing NO conversion at conversions below $\sim 30-60 \%$, depending on gas pressure. At intermediate conversions, energy consumption is constant or slightly increases with increasing conversion. The sharp increase in energy consumption at high NO conversion (98-99\%) is caused by the difficulty of converting byproduct $\mathrm{N}_{2} \mathrm{O}$.

Figures 10(a) and (b) show the variation of energy consumption for NO conversion with gas pressure for different gas residence times, at a fixed power input of $15 \mathrm{~W}$ and at a fixed NO 
conversion of $90 \%$, respectively. The consistent conclusion is that the energy consumption of NO conversion increases with increasing gas pressure, which is explained by the increasing pulse width of the initial discharge voltage peak with increasing gas pressure shown in Table 3 and Figure 1. Namihira et al. (2000) found that the energy required to convert NO increased with increasing pulse width because the interaction time of energetic electrons and gas molecules and the duration of acceleration of the charged species (ions) in the strong electric field during long pulses are increased relative to those experienced during short pulses, which causes more energy to be dissipated thermally. Therefore, the overall energy efficiency of plasma chemical reactions decreases with increasing pulse widths. In addition, Penetrante et al. (1997) found that the fraction of input power consumed in the electron collision process leading to vibrational excitation of $\mathrm{N}_{2}$ increases exponentially with decreasing electron mean energy. The main sources of gas heating are the vibration-translation and vibration-vibration energy relaxation mechanisms of $\mathrm{N}_{2}$ molecules (Gordiets et al., 1995; Guerra et al., 2001). Therefore, with increasing gas pressure, the electron mean energy decreases, which results in dissipation of more energy by gas heating instead of by plasma chemical reactions. Therefore, energy consumption of $\mathrm{NO}_{\mathrm{x}}$ conversion increases with increasing gas pressure, while the energy efficiency for $\mathrm{NO}_{\mathrm{x}}$ conversion, which is inversely related to the energy consumption values shown in Figures 9 and 10, decreases with increasing gas pressure.

\section{Conclusions}

On the basis of experiments designed to understand how the reactor pressure affects the rate of electron collision reactions and energy consumption of $\mathrm{NO}$ conversion in $\mathrm{N}_{2}$, the width of discharge voltage pulses is found to increase with increasing reactor pressure, indicating that 
more energy is dissipated thermally as pressure increases. Model parameter $\alpha$ remains constant with reactor pressure, which proves the previous assumption that electron temperature is inversely proportional to reactor pressure. The dominant kinetic parameter $\beta$, which controls the rate of electron collision reactions, decreases with reactor pressure. Therefore, the rate of electron collision reactions decreases with reactor pressure. A more general expression for the rate constant, Eq. (7), explicitly and accurately accounts for the effect of reactor pressure that used to be contained in $\beta$. In general, energy efficiency of NO conversion increases with decreasing reactor pressure, which is demonstrated at the same power input and at the same NO conversion.

\section{Acknowledgments}

This work was funded by the National Science Foundation (CTS - 9810040; CTS - 0078700) and the Department of Defense (ARO-DAAD19-01-1-0488). The matching support was provided by the Research Office, University of Wyoming. The authors gratefully acknowledge experimental assistance provided by Dr. S. Legowski and Mr. R. Borgialli.

\section{Literature cited}

Abdel-Salam, M., Hashem, A., Yehia, A., Mizuno, A., Turky, A., Gabr, A., 2003. Characteristics of corona and silent discharges as influenced by geometry of the discharge reactor. Journal of Physics D: Applied Physics 36, 252.

Anderson, K. D., 1957. A Study of the Effects of Exhaust Pressure on a Diesel Engine. Master of Science, University of Wyoming.

Atkinson, R., Baulch, D. L., Cox, R. A., Hampson, J. R. F., Kerr, J. A., Rossi, M. J., Troe, J., 1997. Evaluated Kinetic and Photochemical Data for Atmospheric Chemistry: Supplement VI. Journal of Physical and Chemical Reference Data 26, 1329. 
Atkinson, R., Baulch, D. L., Cox, R. A., Hampson, J. R. F., Kerr, J. A., Troe, J., 1989. Evaluated Kinetic and Photochemical Data for Atmospheric Chemistry: Supplement III. Journal of Physical and Chemical Reference Data 18, 881.

Creyghton, Y. L. M., 1994. Pulsed positive corona discharges. Doctor of Philosophy Thesis, Eindhoven University of Technology.

Creyghton, Y. L. M., van Bladel, F. M. A. M., van Veldhuizen, E. M., 1991a. Electrical and Spectroscopic Investigation of Pulsed Positive Streamer Corona in $\mathrm{O}_{2}-\mathrm{N}_{2}$ and $\mathrm{CO}_{2}-\mathrm{O}_{2}$ Mixtures. In: 3rd International Symposium on High Pressure, Low Temperature Plasma Chemistry, Strasbourg, France.

Creyghton, Y. M., van Veldhuizen, E. M., Rutgers, W. R., 1991b. Streamer characteristics of Positive Pulsed Corona. In: 10th International Symposium on Plasma Chemistry: Bochum, Germany.

Gordiets, B. F., Ferreira, C. M., Guerra, V. L., Loureiro, J. M. A. H., Nahorny, J., Pagnon, D., Touzeau, M., Vialle, M., 1995. Kinetic Model of a Low-Pressure $\mathrm{N}_{2}-\mathrm{O}_{2}$ Flowing Glow Discharge. IEEE Transactions on Plasma Science 23, 750.

Guerra, V., Sa, P. A., Loureiro, J., 2001. Role Played by the $\mathrm{N}_{2}\left(\mathrm{~A}^{3} \Sigma_{\mathrm{u}}{ }^{+}\right)$Metastable in Stationary $\mathrm{N}_{2}$ and $\mathrm{N}_{2}-\mathrm{O}_{2}$ Discharges. Journal of Physics D: Applied Physics 34, 1745.

Hackam, R., Akiyama, H., 2000. Air Pollution Control by Electrical Discharges. IEEE Transactions on Dielectrics and Electrical Insulation 7, 654.

Herron, J. T., Green, D. S., 2001. Chemical Kinetics Database and Predictive Schemes for Nonthermal Humid Air Plasma Chemistry. Part II. Neutral Species Reactions. Plasma Chemistry and Plasma Processing 21, 459.

Hu, X., Nicholas, J., Zhang, J. J., Linjewile, T. M., de Filippis, P., Agarwal, P. K., 2002. The Destruction of $\mathrm{N}_{2} \mathrm{O}$ in a Pulsed Corona Discharge Reactor. Fuel 81, 1259.

Hu, X., Zhang, J. J., Mukhnahallipatna, S., Hamann, J., Biggs, M. J., Agarwal, P. K., 2003. Transformations and destruction of nitrogen oxides-NO, $\mathrm{NO}_{2}$ and $\mathrm{N}_{2} \mathrm{O}$-in a pulsed corona discharge reactor. Fuel 82, 1675.

Huang, J., Suib, S. L., 1993. Dimerization of methane through microwave plasmas. Journal of Physical Chemistry 97, 9403.

Kossyi, I. A., Kostinsky, A. Y., Matveyev, A. A., Silakov, V. P., 1992. Kinetic Scheme of the Non-equilibrium Discharge in Nitrogen-Oxygen Mixtures. Plasma Sources Science and Technology 1, 207.

Lilly, L. C. R., 1984. Diesel Engine Reference Book; Butterworths, Boston. 
Lowke, J. J., Morrow, R., 1995. Theoretical Analysis of Removal of Oxides of Sulphur and Nitrogen in Pulsed Operation of Electrostatic Precipitators. IEEE Transactions on Plasma Science 23, 661.

Mizuno, A., Shimizu, K., Chakrabarti, A., Dascalescu, L., Furuta, S., 1995. NO Removal Process Using Pulsed Discharge Plasma. IEEE Transactions on Industry Applications 31, 957.

Mok, Y. S., Ham, S. W., Nam, I. S., 1998. Mathematical Analysis of Positive Pulsed Corona Discharge Process Employed for Removal of Nitrogen Oxides. IEEE Transactions on Plasma Science 26, 1566.

Namihira, T., Tsukamoto, S., Wang, D., Hori, H., Katsuki, S., Hackam, R., Akiyama, H., Shimizu, M., Yokoyama, K., 2001. Influence of Gas Flow Rate and Reactor Length on NO Removal Using Pulsed Power. IEEE Transactions on Plasma Science 29, 592.

Namihira, T., Tsukamoto, S., Wang, D., Katsuki, S., Hackam, R., Akiyama, H., Uchida, Y., Koike, M., 2000. Improvement of $\mathrm{NO}_{\mathrm{x}}$ Removal Efficiency Using Short-Width Pulsed Power. IEEE Transactions on Plasma Science 28, 434.

Penetrante, B. M., Bardsley, J. N., Hsiao, M. C., 1997. Kinetic analysis of non-thermal plasmas used for pollution control. Japanese Journal of Applied Physics 36, 5007.

Penetrante, B. M., Hsiao, M. C., Merritt, B. T., Vogtlin, G. E., Wallman, P. H., 1995. Comparison of Electrical Discharge Techniques for Nonthermal Plasma Processing of NO in $\mathrm{N}_{2}$. IEEE Transactions on Plasma Science 23, 679.

Puchkarev, V., Gundersen, M., 1997. Energy Efficient Plasma Processing of Gaseous Emission Using a Short Pulse Discharge. Applied Physics Letters 71, 3364.

Raether, H., 1964. Electron Avalanches and Breakdown in Gases; Butterworths, Washington.

Sigmond, R. S., 1984. The residual streamer channel: Return strokes and secondary streamers. Journal of Applied Physics 56, 1355.

Spiliopoulos, N., Mataras, D., Rapakoulias, D. E., 1997. Arrhenius-like behavior in plasma reactions. Applied Physics Letters 71, 605.

Starikovskaia, S. M., Anikin, N. B., Pancheshnyi, S. V., Zatsepin, D. V., Starikovskii, A. Y., 2001. Pulsed breakdown at high overvoltage:development, propagation and energy branching. Plasma Sources Science and Technology 10, 344.

van Veldhuizen, E. M., Creyghton, Y. L. M., Rutgers, W. R., 1990. High Resolution Schlieren Study of Pulsed Corona. In: Proceedings of 4th International Conference on ESP, Beijing, China. 
Yamamoto, T., Yang, C. L., Beltran, M. R., Kravets, Z., 2000. Plasma-Assisted Chemical Process for $\mathrm{NO}_{\mathrm{x}}$ Control. IEEE Transactions on Industry Applications 36, 923.

Zhao, G. -B., Garikipati, S. V. B. J., Hu, X., Argyle, M. D., Radosz, M., 2004a. The Effect of Reactor Configuration on Nitric Oxide Conversion in Nitrogen Plasma. A. I. Ch. E. Journal (in press).

Zhao, G. -B., Hu, X., Argyle, M. D., Radosz, M., 2004b. N Atom and $\mathrm{N}_{2}\left(\mathrm{~A}^{3} \Sigma_{\mathrm{u}}{ }^{+}\right)$Found to be Responsible for Nitrogen Oxides Conversion in Nonthermal Nitrogen Plasma. Industrial \& Engineering Chemistry Research 43, 5077.

Zhao, G. -B., Hu, X., Plumb, O. A., Radosz, M., 2004c. Energy consumption and optimal reactor configuration for nonthermal plasma conversion of $\mathrm{N}_{2} \mathrm{O}$ in nitrogen and $\mathrm{N}_{2} \mathrm{O}$ in Argon. Energy \& Fuels 18, 1522.

Zhao, G. -B., Hu, X., Yeung, M. C., Plumb, O. A., Radosz, M., 2004d. Nonthermal Plasma Reactions of Dilute Nitrogen Oxide Mixtures: $\mathrm{NO}_{\mathrm{x}}$ in Nitrogen. Industrial \& Engineering Chemistry Research 43, 2315. 


\section{Table Captions}

Table 1. Experimental Matrix

Table 2. List of chemical reactions used in modeling the NO in $\mathrm{N}_{2}$ system

Table 3. Influence of reactor pressure on the discharge parameters in a two-tube reactor at $200 \mathrm{~Hz}$ pulse frequency

Table 4. Model parameters at different pressure for one, two and ten-tube reactor 
Table 1. Experiment matrix

\begin{tabular}{|c|c|c|c|}
\hline $\begin{array}{c}\text { Reactor tube } \\
\text { number }\end{array}$ & $\begin{array}{c}\text { Reactor pressure } \\
(\mathrm{atm})\end{array}$ & System & Flowrate $\left(\mathrm{m}^{3} / \mathrm{s}\right)$ \\
\hline \multirow{3}{*}{1} & 1.46 & $595 \mathrm{ppm} \mathrm{NO}+\mathrm{N}_{2}$ & $2.01 \times 10^{-4}$ \\
\cline { 2 - 4 } & 2.14 & $240 \mathrm{ppm} \mathrm{NO}+\mathrm{N}_{2}$ & $8.82 \times 10^{-5}$ \\
\cline { 2 - 4 } & 2.82 & $240 \mathrm{ppm} \mathrm{NO}+\mathrm{N}_{2}$ & $5.47 \times 10^{-5}$ \\
\hline \multirow{3}{*}{2} & 1.46 & $595 \mathrm{ppm} \mathrm{NO}+\mathrm{N}_{2}$ & $1.02 \times 10^{-4}$ \\
\cline { 2 - 4 } & 1.80 & $593 \mathrm{ppm} \mathrm{NO}+\mathrm{N}_{2}$ & $1.62 \times 10^{-4}$ \\
\cline { 2 - 4 } & 2.14 & $595 \mathrm{ppm} \mathrm{NO}+\mathrm{N}_{2}$ & $1.72 \times 10^{-4}$ \\
\cline { 2 - 4 } & 2.48 & $593 \mathrm{ppm} \mathrm{NO}+\mathrm{N}_{2}$ & $1.22 \times 10^{-4}$ \\
\cline { 2 - 4 } & 2.82 & $595 \mathrm{ppm} \mathrm{NO}+\mathrm{N}_{2}$ & $1.13 \times 10^{-4}$ \\
\cline { 2 - 4 } & 1.46 & $593 \mathrm{ppm} \mathrm{NO}+\mathrm{N}_{2}$ & $3.70 \times 10^{-4}$ \\
\cline { 2 - 4 } & 2.14 & $655 \mathrm{ppm} \mathrm{NO}+\mathrm{N}_{2}$ & $1.71 \times 10^{-4}$ \\
\hline
\end{tabular}


Table 2. List of chemical reactions used in modeling the NO in $\mathrm{N}_{2}$ system

\begin{tabular}{|c|c|c|c|}
\hline Chemical reaction & $\begin{array}{l}\text { Rate constant } \\
\left(\mathrm{cm}^{3} \cdot \mathrm{mol}^{-1} \cdot \mathrm{s}^{-1}\right)\end{array}$ & Source & No. \\
\hline $\mathrm{N}_{2}+\mathrm{e} \rightarrow \mathrm{N}+\mathrm{N}+\mathrm{e}$ & $k_{1}=\frac{\beta_{1}}{[e]} \sqrt{\frac{1}{\alpha_{1} P}} W^{0.75} \exp \left(-\frac{\alpha_{1} P}{W}\right)$ & This work & R1 \\
\hline $\mathrm{N}_{2}+\mathrm{e} \rightarrow \mathrm{N}_{2}(\mathrm{~A})+\mathrm{e}$ & $k_{2}=\frac{\beta_{2}}{[e]} \sqrt{\frac{1}{\alpha_{2} P}} W^{0.75} \exp \left(-\frac{\alpha_{2} P}{W}\right)$ & This work & R2 \\
\hline $\mathrm{N}+\mathrm{NO} \rightarrow \mathrm{N}_{2}+\mathrm{O}$ & $1.87 \times 10^{13}$ & (Atkinson et al., 1989) & R3 \\
\hline $\mathrm{O}+\mathrm{NO}+\mathrm{N}_{2} \rightarrow \mathrm{NO}_{2}+\mathrm{N}_{2}$ & $\begin{array}{l}\mathrm{k}_{0}=3.62 \times 10^{16}\left[\mathrm{~N}_{2}\right] \\
\mathrm{k}_{\infty}=1.81 \times 10^{13} \\
\mathrm{FC}=0.85\end{array}$ & (Atkinson et al., 1997) & R4 \\
\hline $\mathrm{NO}_{2}+\mathrm{N} \rightarrow \mathrm{N}_{2} \mathrm{O}+\mathrm{O}$ & $1.81 \times 10^{12}$ & (Atkinson et al., 1989) & R5 \\
\hline $\mathrm{NO}_{2}+\mathrm{N} \rightarrow \mathrm{N}_{2}+\mathrm{O}_{2}$ & $4.21 \times 10^{11}$ & (Kossyi et al., 1992) & R6 \\
\hline $\mathrm{NO}_{2}+\mathrm{N} \rightarrow \mathrm{N}_{2}+2 \mathrm{O}$ & $5.48 \times 10^{11}$ & (Kossyi et al., 1992) & R7 \\
\hline $\mathrm{NO}_{2}+\mathrm{N} \rightarrow 2 \mathrm{NO}$ & $1.38 \times 10^{12}$ & (Kossyi et al., 1992) & R8 \\
\hline $\mathrm{NO}_{2}+\mathrm{O} \rightarrow \mathrm{NO}+\mathrm{O}_{2}$ & $5.85 \times 10^{12}$ & (Atkinson et al., 1997) & R9 \\
\hline $\mathrm{N}_{2}(\mathrm{~A})+\mathrm{NO} \rightarrow \mathrm{N}_{2}+\mathrm{NO}$ & $3.31 \times 10^{13}$ & (Herron and Green, 2001) & R10 \\
\hline $\mathrm{N}_{2}(\mathrm{~A})+\mathrm{N}_{2} \mathrm{O} \rightarrow 2 \mathrm{~N}_{2}+\mathrm{O}$ & $3.73 \times 10^{12}$ & (Herron and Green, 2001) & R11 \\
\hline $\mathrm{N}_{2}(\mathrm{~A})+\mathrm{NO}_{2} \rightarrow \mathrm{N}_{2}+\mathrm{NO}+\mathrm{O}$ & $7.83 \times 10^{12}$ & (Herron and Green, 2001) & R12 \\
\hline $\mathrm{N}_{2}(\mathrm{~A})+\mathrm{O}_{2} \rightarrow \mathrm{N}_{2}+2 \mathrm{O}$ & $1.51 \times 10^{12}$ & (Herron and Green, 2001) & R13 \\
\hline $\mathrm{N}_{2}(\mathrm{~A})+\mathrm{O}_{2} \rightarrow \mathrm{N}_{2} \mathrm{O}+\mathrm{O}$ & $4.70 \times 10^{10}$ & (Kossyi et al., 1992) & R14 \\
\hline $\mathrm{N}_{2}(\mathrm{~A})+\mathrm{O}_{2} \rightarrow \mathrm{N}_{2}+\mathrm{O}_{2}$ & $7.77 \times 10^{11}$ & (Kossyi et al., 1992) & R15 \\
\hline $\mathrm{N}_{2}(\mathrm{~A})+\mathrm{O} \rightarrow \mathrm{N}_{2}+\mathrm{O}$ & $1.81 \times 10^{13}$ & (Herron and Green, 2001) & R16 \\
\hline $\mathrm{N}_{2}(\mathrm{~A})+\mathrm{N} \rightarrow \mathrm{N}_{2}+\mathrm{N}$ & $2.71 \times 10^{13}$ & (Herron and Green, 2001) & R17 \\
\hline $\mathrm{N}+\mathrm{N}+\mathrm{N}_{2} \rightarrow \mathrm{N}_{2}+\mathrm{N}_{2}$ & $1.59 \times 10^{15}\left[\mathrm{~N}_{2}\right]$ & (Kossyi et al., 1992) & R18 \\
\hline $\mathrm{O}+\mathrm{O}+\mathrm{N}_{2} \rightarrow \mathrm{O}_{2}+\mathrm{N}_{2}$ & $1.10 \times 10^{15}\left[\mathrm{~N}_{2}\right]$ & (Kossyi et al., 1992) & R19 \\
\hline $\mathrm{N}+\mathrm{O}+\mathrm{N}_{2} \rightarrow \mathrm{NO}+\mathrm{N}_{2}$ & $3.68 \times 10^{15}\left[\mathrm{~N}_{2}\right]$ & (Kossyi et al., 1992) & R20 \\
\hline
\end{tabular}


Table 3. Influence of reactor pressure on the discharge parameters in a two-tube reactor at $200 \mathrm{~Hz}$ pulse frequency

\begin{tabular}{|c|c|c|c|}
\hline Gas pressure (atm) & Pulse peak (kV) & Pulse width (ns) & Rise rate (kV/ns) \\
\hline 1.46 & 18.3 & 47 & 1.33 \\
\hline 1.80 & 19.0 & 57 & 1.33 \\
\hline 2.14 & 19.0 & 83 & 1.39 \\
\hline 2.48 & 19.8 & 429 & 1.38 \\
\hline 2.82 & 19.9 & $>500$ & 1.31 \\
\hline
\end{tabular}


Table 4. Model parameters at different pressure for one, two and ten-tube reactor

\begin{tabular}{|c|c|c|c|c|}
\hline \multicolumn{3}{|c|}{ Electron collision reaction } & R1 & R2 \\
\hline \multirow{9}{*}{ One-tube reactor } & \multirow{3}{*}{$\begin{array}{c}\alpha \\
\left(\mathrm{J} \cdot \mathrm{atm}^{-1} \cdot \mathrm{s}^{-1}\right)\end{array}$} & $1.46 \mathrm{~atm}$ & 3.68 & 5.10 \\
\hline & & $2.14 \mathrm{~atm}$ & 3.68 & 5.10 \\
\hline & & $2.82 \mathrm{~atm}$ & 3.68 & 5.10 \\
\hline & \multirow{3}{*}{$\begin{array}{c}\beta \\
\left(J^{-0.25} \cdot \mathrm{s}^{-0.75}\right)\end{array}$} & $1.46 \mathrm{~atm}$ & $1.09 \times 10^{-5}$ & $1.68 \times 10^{-4}$ \\
\hline & & $2.14 \mathrm{~atm}$ & $7.69 \times 10^{-6}$ & $1.19 \times 10^{-4}$ \\
\hline & & $2.82 \mathrm{~atm}$ & $6.00 \times 10^{-6}$ & $9.28 \times 10^{-5}$ \\
\hline & \multirow{3}{*}{$\begin{array}{c}\text { B } \\
\left(\mathrm{J}^{-0.25} \cdot \mathrm{s}^{-0.75} \cdot \mathrm{atm}^{0.9}\right)\end{array}$} & $1.46 \mathrm{~atm}$ & $1.52 \times 10^{-5}$ & $2.36 \times 10^{-4}$ \\
\hline & & $2.14 \mathrm{~atm}$ & $1.52 \times 10^{-5}$ & $2.36 \times 10^{-4}$ \\
\hline & & $2.82 \mathrm{~atm}$ & $1.52 \times 10^{-5}$ & $2.36 \times 10^{-4}$ \\
\hline \multirow{15}{*}{ Two-tube reactor } & \multirow{5}{*}{$\begin{array}{c}\alpha \\
\left(\mathrm{J} \cdot \mathrm{atm}^{-1} \cdot \mathrm{s}^{-1}\right)\end{array}$} & $1.46 \mathrm{~atm}$ & 3.88 & 4.94 \\
\hline & & $1.80 \mathrm{~atm}$ & 4.23 & 4.86 \\
\hline & & $2.14 \mathrm{~atm}$ & 3.95 & 5.26 \\
\hline & & $2.48 \mathrm{~atm}$ & 4.06 & 4.99 \\
\hline & & $2.82 \mathrm{~atm}$ & 4.21 & 4.91 \\
\hline & \multirow{5}{*}{$\begin{array}{c}\beta \\
\left(J^{-0.25} \cdot \mathrm{s}^{-0.75}\right)\end{array}$} & $1.46 \mathrm{~atm}$ & $9.79 \times 10^{-6}$ & $7.37 \times 10^{-5}$ \\
\hline & & $1.80 \mathrm{~atm}$ & $8.22 \times 10^{-6}$ & $6.10 \times 10^{-5}$ \\
\hline & & $2.14 \mathrm{~atm}$ & $7.31 \times 10^{-6}$ & $5.09 \times 10^{-5}$ \\
\hline & & $2.48 \mathrm{~atm}$ & $6.32 \times 10^{-6}$ & $4.31 \times 10^{-5}$ \\
\hline & & $2.82 \mathrm{~atm}$ & $5.70 \times 10^{-6}$ & $3.85 \times 10^{-5}$ \\
\hline & \multirow{5}{*}{$\begin{array}{c}\text { B } \\
\left(\mathrm{J}^{-0.25} \cdot \mathrm{s}^{-0.75} \cdot \mathrm{atm}^{0.9}\right)\end{array}$} & $1.46 \mathrm{~atm}$ & $1.41 \times 10^{-5}$ & $1.02 \times 10^{-4}$ \\
\hline & & $1.80 \mathrm{~atm}$ & $1.41 \times 10^{-5}$ & $1.02 \times 10^{-4}$ \\
\hline & & $2.14 \mathrm{~atm}$ & $1.41 \times 10^{-5}$ & $1.02 \times 10^{-4}$ \\
\hline & & $2.48 \mathrm{~atm}$ & $1.41 \times 10^{-5}$ & $1.02 \times 10^{-4}$ \\
\hline & & $2.82 \mathrm{~atm}$ & $1.41 \times 10^{-5}$ & $1.02 \times 10^{-4}$ \\
\hline \multirow{6}{*}{ Ten-tube reactor } & \multirow{2}{*}{$\begin{array}{c}\alpha \\
\left(\mathrm{J} \cdot \mathrm{atm}^{-1} \cdot \mathrm{s}^{-1}\right)\end{array}$} & $1.46 \mathrm{~atm}$ & 3.20 & 4.98 \\
\hline & & $2.14 \mathrm{~atm}$ & 3.20 & 4.98 \\
\hline & \multirow{2}{*}{$\begin{array}{c}\beta \\
\left(\mathrm{J}^{-0.25} \cdot \mathrm{s}^{-0.75}\right)\end{array}$} & $1.46 \mathrm{~atm}$ & $3.70 \times 10^{-6}$ & $8.34 \times 10^{-6}$ \\
\hline & & $2.14 \mathrm{~atm}$ & $2.62 \times 10^{-6}$ & $5.90 \times 10^{-6}$ \\
\hline & \multirow{2}{*}{$\begin{array}{c}\mathrm{B} \\
\left(\mathrm{J}^{-0.25} \cdot \mathrm{s}^{-0.75} \cdot \mathrm{atm}^{0.9}\right)\end{array}$} & $1.46 \mathrm{~atm}$ & $5.18 \times 10^{-6}$ & $1.17 \times 10^{-5}$ \\
\hline & & $2.14 \mathrm{~atm}$ & $5.18 \times 10^{-6}$ & $1.17 \times 10^{-5}$ \\
\hline
\end{tabular}




\section{Figure Captions}

Figure 1.Effect of reactor pressure on the discharge voltage waveform. (Two-tube reactor, 200 $\mathrm{Hz}$ pulse frequency)

Figure 2.Experimental and Correlated data for $\mathrm{NO}_{\mathrm{x}}$ exit concentrations in the two-tube reactor at different overall reactor pressures. (a) $1.46 \mathrm{~atm}$, (b) $1.80 \mathrm{~atm}$, (c) $2.14 \mathrm{~atm}$, (d) 2.48 atm, (e) 2.82 atm. Experimental data: $\mathbf{a}(\mathrm{NO}), \mathbf{0}\left(\mathrm{NO}_{2}\right), \boldsymbol{\Delta}\left(\mathrm{N}_{2} \mathrm{O}\right)$; Calculated data including two electron collision reactions R1 and R2 (-)

Figure 3.Effect of reactor pressure on model parameter $\alpha$ for electron collision reactions in the two-tube reactor. Experimental data: $\mathbf{\square}(\mathrm{R} 1), \boldsymbol{\Delta}(\mathrm{R} 2)$

Figure 4.Effect of reactor pressure on model parameter $\beta$ for electron collision reactions in the two-tube reactor. (a) Electron collision reaction R1, (b) electron collision reaction R2. Experimental data: $\mathbf{\square}$, Least square regression: $-\beta \propto \mathrm{P}^{-0.9}$

Figure 5.Rate constant of electron collision reactions as a function of power input for different gas pressures. (a) Electron collision reaction R1, (b) electron collision reaction R2 (-, 1.46 atm; ---, 1.80 atm; ....., 2.14 atm; -.---, 2.48 atm; -..-, 2.82 atm)

Figure 6.Experimental and predicted outlet $\mathrm{NO}_{\mathrm{x}}$ concentrations in one-tube reactor at 2.14 atm. (a) $\mathrm{NO}$, (b) $\mathrm{NO}_{2}$, (c) $\mathrm{N}_{2} \mathrm{O}$. Experimental data (a), Calculated data (-)

Figure 7.Experimental and predicted outlet $\mathrm{NO}_{\mathrm{x}}$ concentrations in one-tube reactor at 2.82 atm.

(a) $\mathrm{NO}$, (b) $\mathrm{NO}_{2}$, (c) $\mathrm{N}_{2} \mathrm{O}$. Experimental data (匹), Calculated data (-)

Figure 8.Experimental and predicted outlet $\mathrm{NO}_{\mathrm{x}}$ concentrations in ten-tube reactor at 2.14 atm. (a) $\mathrm{NO}$, (b) $\mathrm{NO}_{2}$, (c) $\mathrm{N}_{2} \mathrm{O}$. Experimental data (घ), Calculated data (-)

Figure 9.Effect of reactor pressure on $\mathrm{NO}_{\mathrm{x}}$ conversion and energy consumption in two-tube reactor at gas residence time of $6 \mathrm{~s}$. (a) $\mathrm{NO}_{\mathrm{x}}$ conversion as a function of power input, (b) energy consumption as a function of power input, (c) energy consumption as a function of $\mathrm{NO}_{\mathrm{x}}$ conversion.

(-, 1.46 atm; ---, 1.80 atm; …., 2.14 atm; -.---, 2.48 atm; -..-, 2.82 atm)

Figure 10.Energy consumption during NO conversion as a function of reactor pressure in a twotube reactor. (a) Power input of 15W, (b) $90 \%$ conversion Experimental data: $\square$, 6s, $\bigcirc$, 9s, $\triangle$, $12 \mathrm{~s}, \nabla$, $15 \mathrm{~s}$ gas residence time 

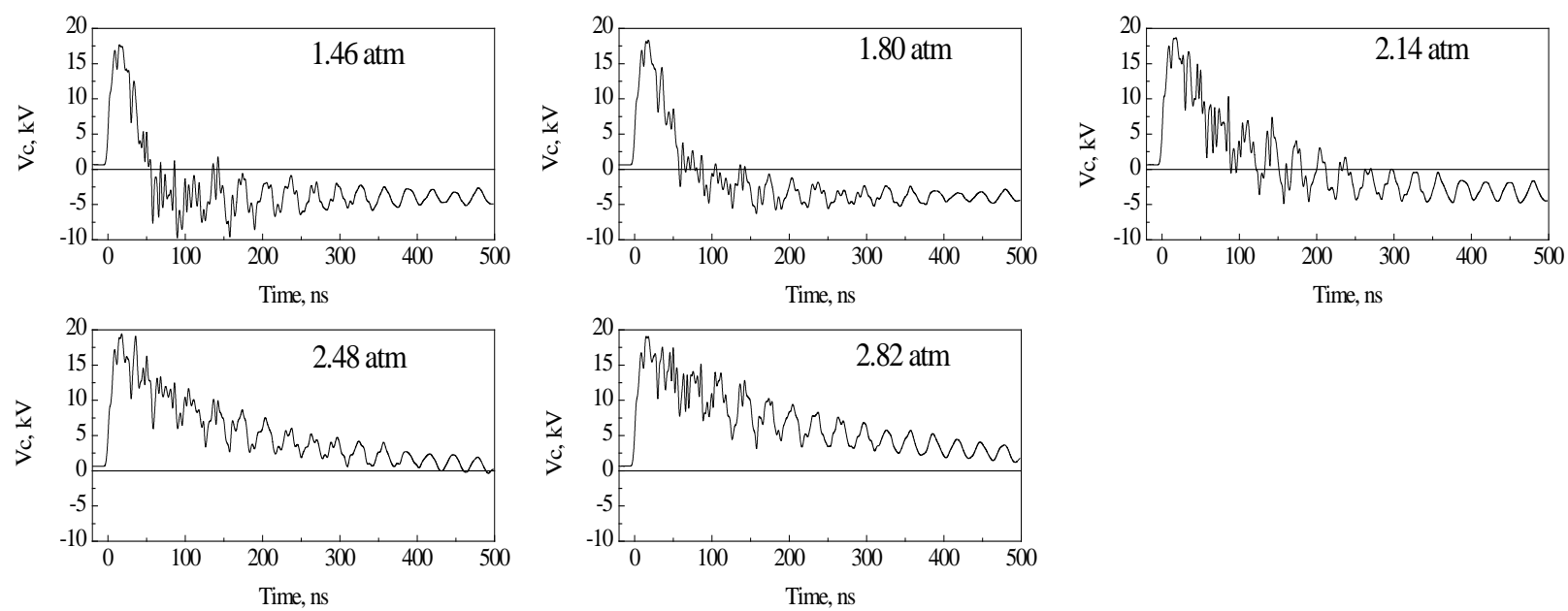

Figure 1. Effect of reactor pressure on the discharge voltage waveform. (Two-tube reactor, 200 $\mathrm{Hz}$ pulse frequency)

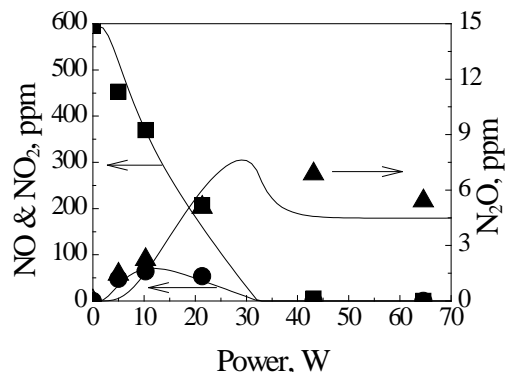

(a)

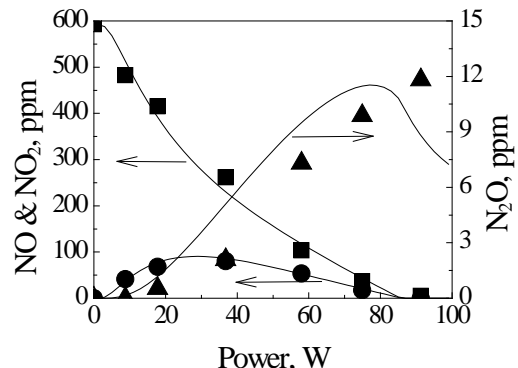

(d)

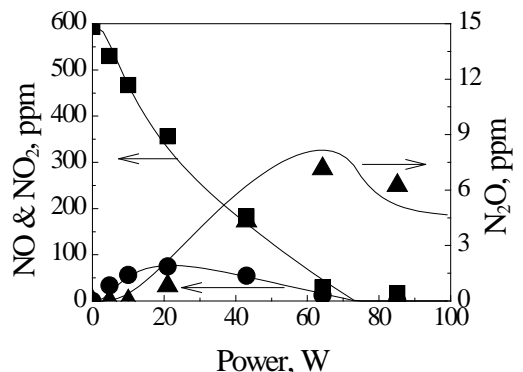

(b)

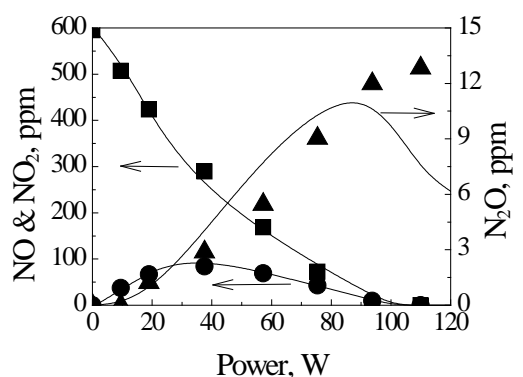

(e)

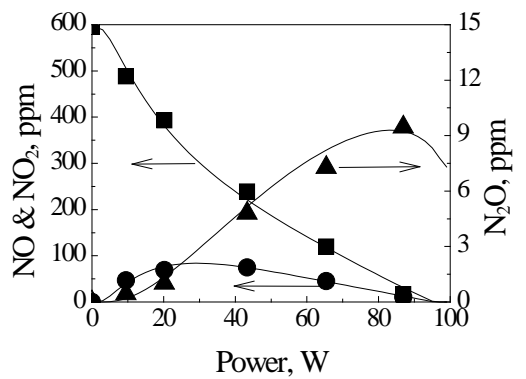

(c)

Figure 2. Experimental and Correlated data for $\mathrm{NO}_{\mathrm{x}}$ exit concentrations in the two-tube reactor at different overall reactor pressures. (a) $1.46 \mathrm{~atm}$, (b) $1.80 \mathrm{~atm}$, (c) $2.14 \mathrm{~atm}$, (d) 2.48

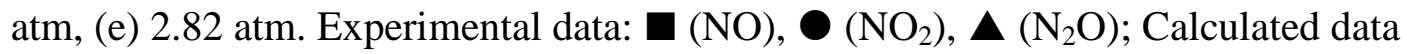
including two electron collision reactions R1 and R2 (- 


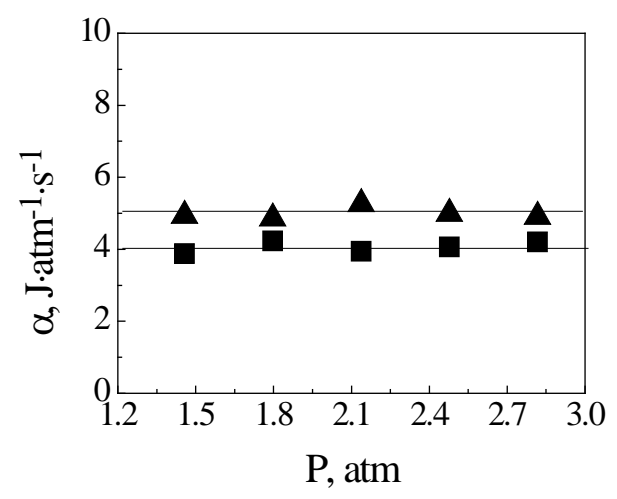

Figure 3. Effect of reactor pressure on model parameter $\alpha$ for electron collision reactions in the two-tube reactor. Experimental data: $\mathbf{\square}(\mathrm{R} 1), \boldsymbol{\Delta}(\mathrm{R} 2)$

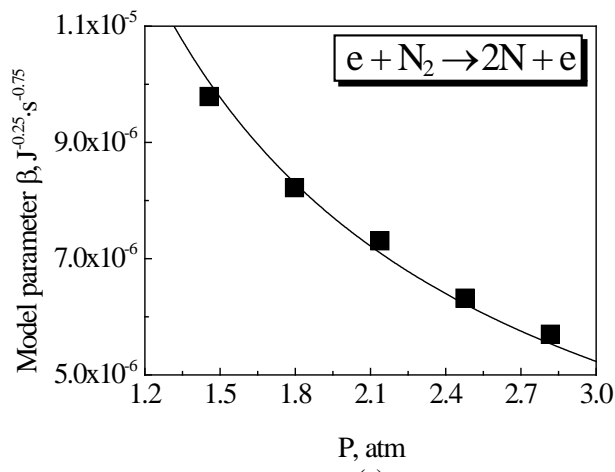

(a)

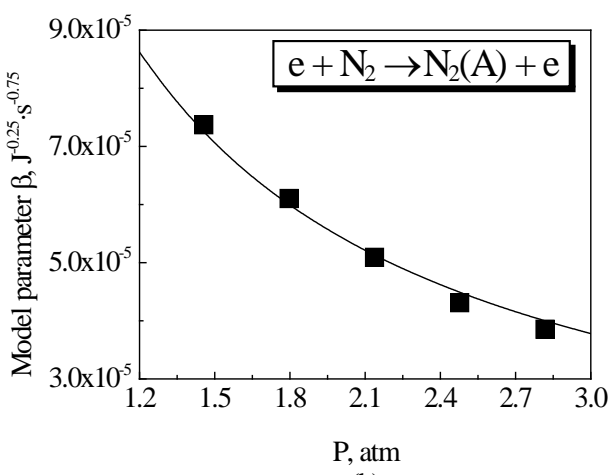

(b)

Figure 4. Effect of reactor pressure on model parameter $\beta$ for electron collision reactions in the two-tube reactor. (a) Electron collision reaction R1, (b) electron collision reaction R2. Experimental data: $\mathbf{\square}$, Least square regression: $-\beta \propto \mathrm{P}^{-0.9}$

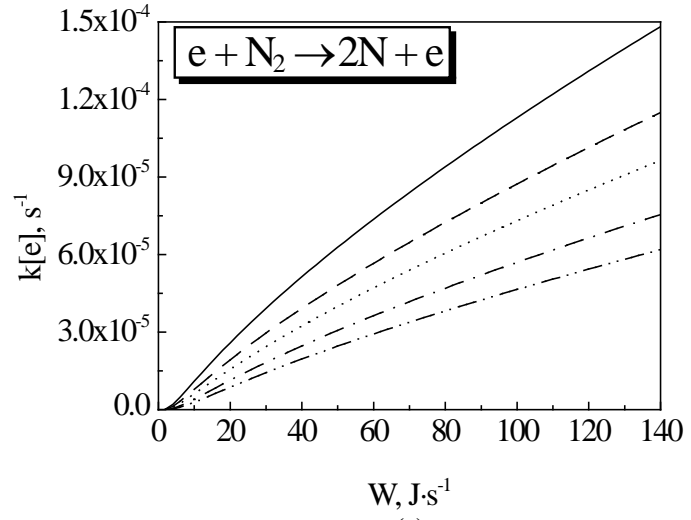

(a)

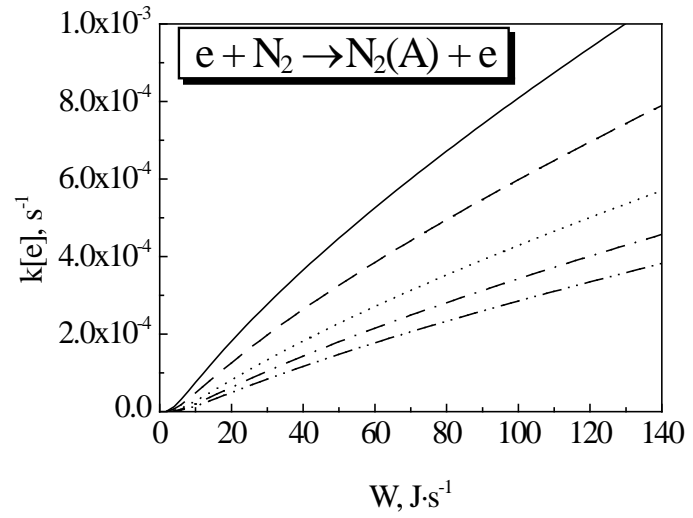

(b)

Figure 5. Rate constant of electron collision reactions as a function of power input for different gas pressures. (a) Electron collision reaction R1, (b) electron collision reaction R2 (-, 1.46 atm; ---, 1.80 atm; ….., 2.14 atm; -.-.-, 2.48 atm; -..-, 2.82 atm) 


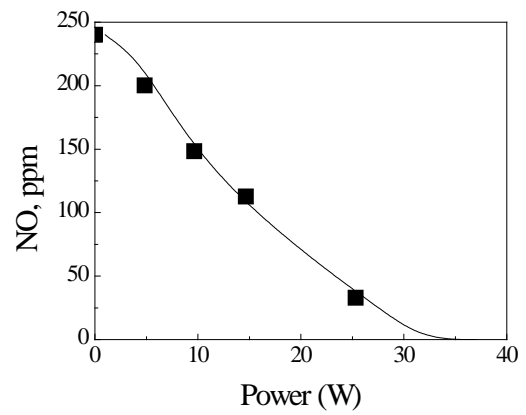

(a)

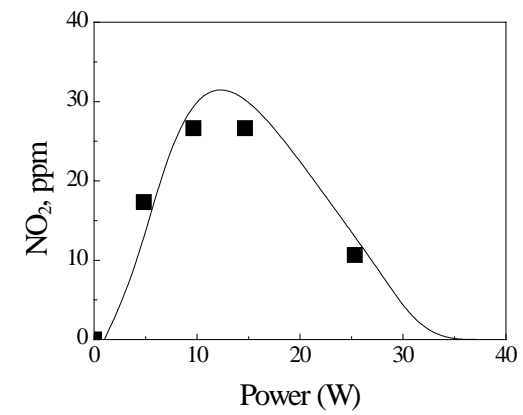

(b)

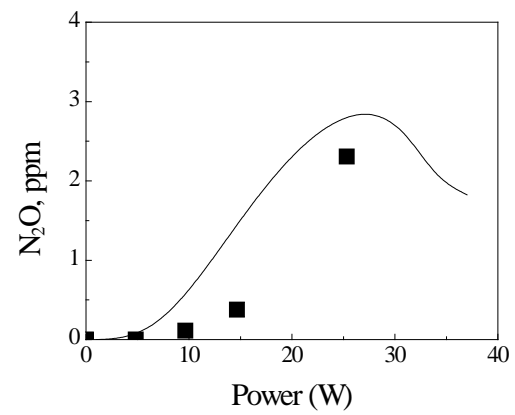

(c)

Figure 6. Experimental and predicted outlet $\mathrm{NO}_{\mathrm{x}}$ concentrations in one-tube reactor at 2.14 atm.

(a) $\mathrm{NO}$, (b) $\mathrm{NO}_{2}$, (c) $\mathrm{N}_{2} \mathrm{O}$. Experimental data (匹), Calculated data (-)

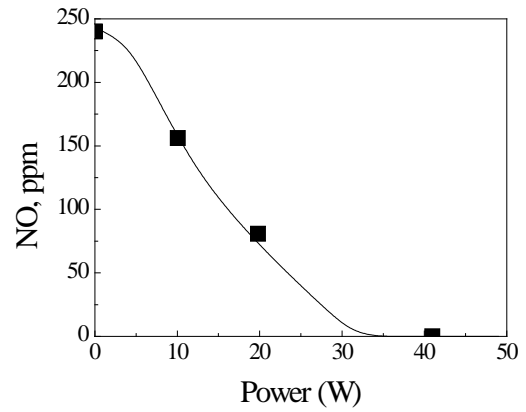

(a)

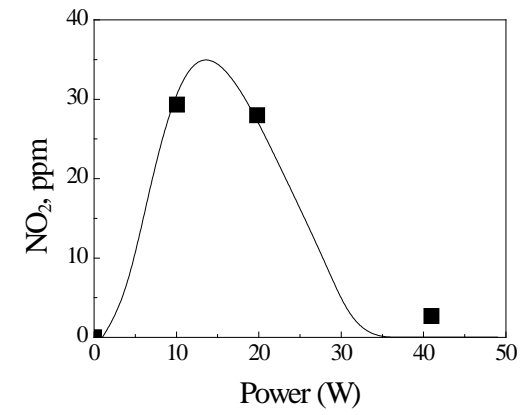

(b)

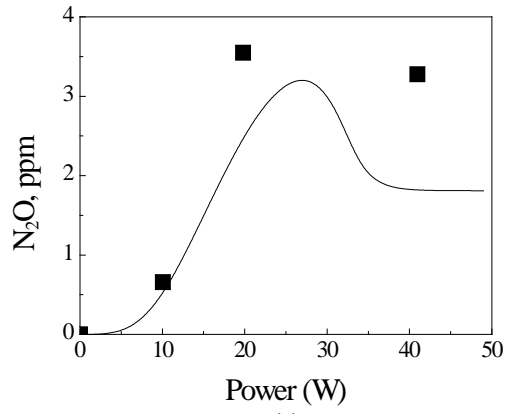

(c)

Figure 7. Experimental and predicted outlet $\mathrm{NO}_{\mathrm{x}}$ concentrations in one-tube reactor at 2.82 atm.

(a) $\mathrm{NO}$, (b) $\mathrm{NO}_{2}$, (c) $\mathrm{N}_{2} \mathrm{O}$. Experimental data (a), Calculated data (-)

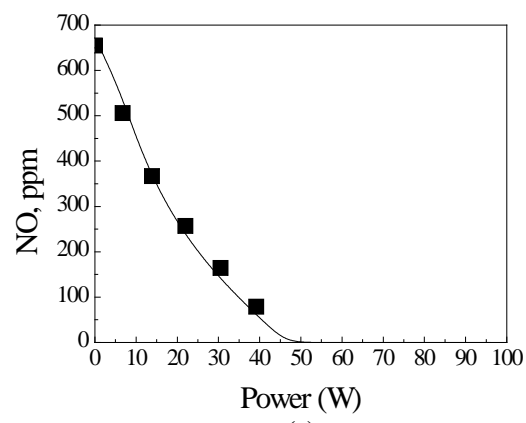

(a)

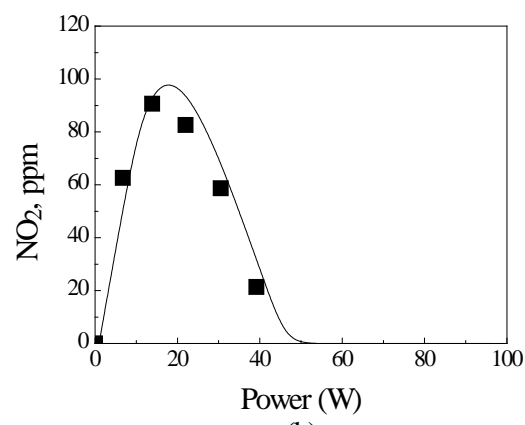

(b)

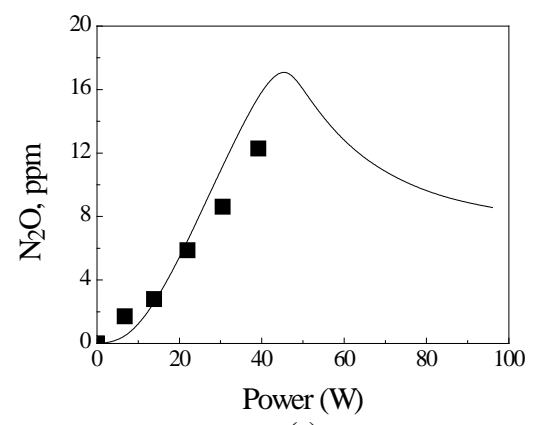

(c)

Figure 8. Experimental and predicted outlet $\mathrm{NO}_{\mathrm{x}}$ concentrations in ten-tube reactor at 2.14 atm.

(a) $\mathrm{NO}$, (b) $\mathrm{NO}_{2}$, (c) $\mathrm{N}_{2} \mathrm{O}$. Experimental data (a), Calculated data (-) 


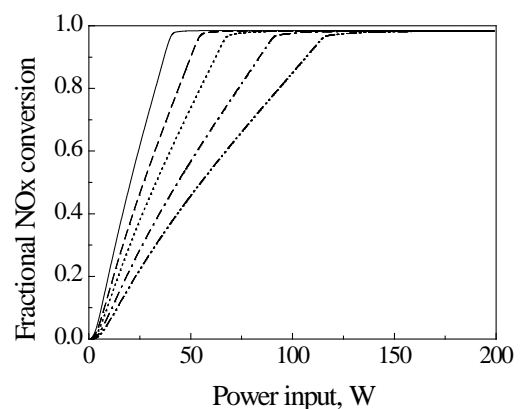

(a)

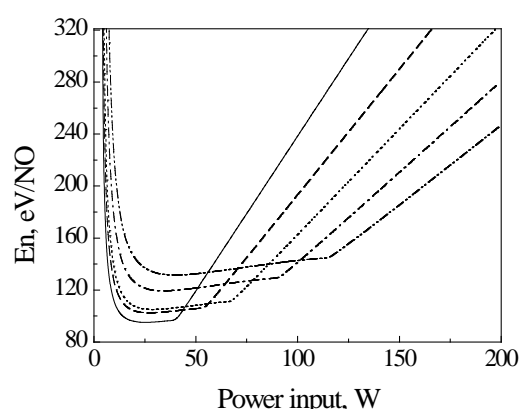

(b)

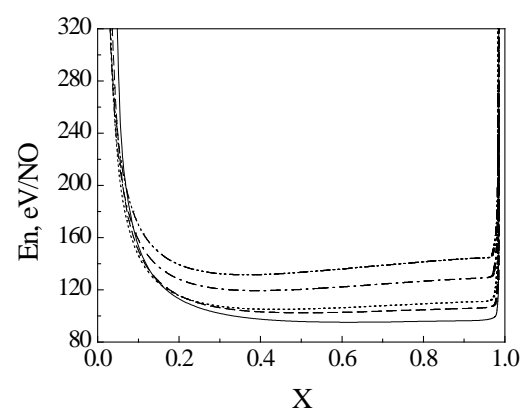

(c)

Figure 9. Effect of reactor pressure on $\mathrm{NO}_{\mathrm{x}}$ conversion and energy consumption in two-tube reactor at gas residence time of $6 \mathrm{~s}$. (a) $\mathrm{NO}_{\mathrm{x}}$ conversion as a function of power input, (b) energy consumption as a function of power input, (c) energy consumption as a function of $\mathrm{NO}_{\mathrm{x}}$ conversion.

$$
\text { (-, } 1.46 \text { atm; ----, } 1.80 \text { atm; …., } 2.14 \text { atm; -.-.-, } 2.48 \text { atm; -..-, } 2.82 \text { atm) }
$$

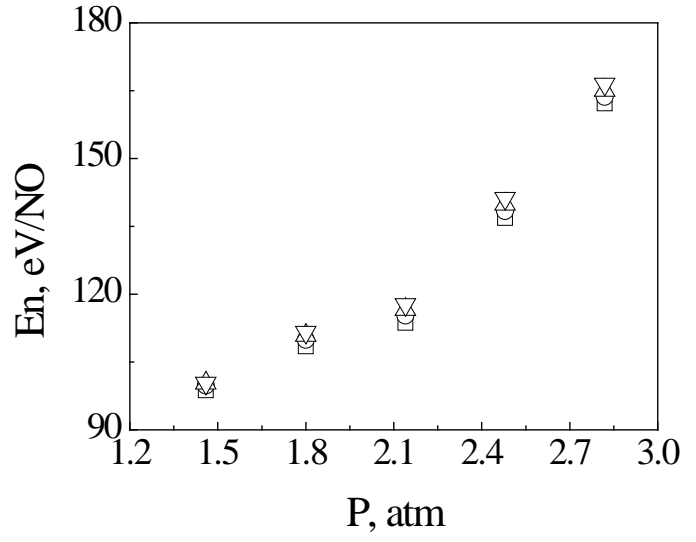

(a)

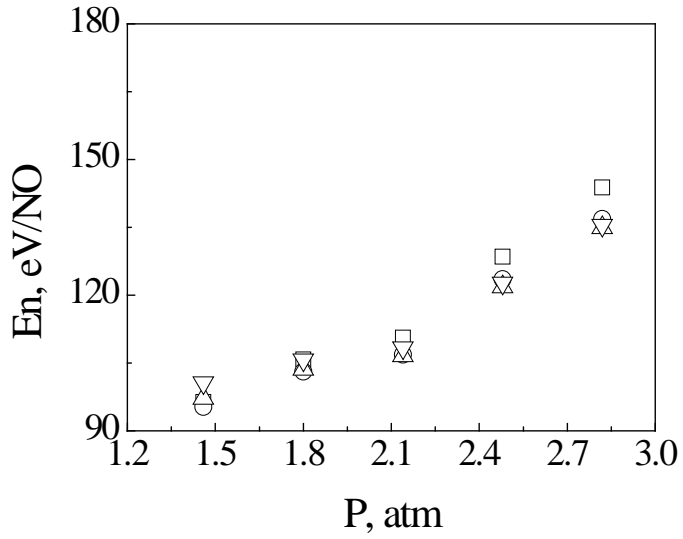

(b)

Figure 10. Energy consumption during NO conversion as a function of reactor pressure in a two-tube reactor. (a) Power input of 15W, (b) $90 \%$ conversion Experimental data: $\square$, 6s, $\bigcirc, 9 \mathrm{~s}, \triangle$, 12s, $\nabla, 15$ s gas residence time 